\title{
Perpetuating Old Mindsets through New Civic Education Textbooks: The Case of Post-communist Albania
}

\author{
Dr. Grida Duma
}

\section{Doi:10.5901/ajis.2016.v5n1p237}

\section{Abstract}

This article looks into the end-user impact of the civic education curricula in Albania. It discusses their goals, achievements and gaps by reviewing its processes, stakeholders and the final body of knowledge provided to school students through the civic education classes taught in the $9^{\text {th }}$, 10th and 11th classes in the Republic of Albania. It concludes that civic education texts presently used in Albania's high schools suffer from a plethora of problems ranging from weak contents and ineffective transfer of notions to poor illustrations of concepts, contributing to the overall low impact of the subject of civic education on the students. The failure to address the low quality of the civic education textbooks in Albania at the input side and the deterioration of the delivery of civics into a merely formal process at the output side are two significant indicators that stand for the perpetuation of a culture of apathy in a country still struggling to come to terms with liberal democracy.

\section{Introduction}

Autopoiesis is well-established paradigm for accounting for the self-referential reproduction of society, its mores, habits, and institutions. My case on the perpetuation of "old-time" mindsets through "new educational instruments" regards the self-referential reproduction of that part of civic apathy that can be accounted for by the effects yield by the new civic education curricula in Albania on their end users - students aged $16-18$ years' old. By "old mindsets" I mean in no way anything older than the prevailing frame of mind of Albanians at the last stages of the Albania's communist system and its chaotic transformation over the first years of post-communist transition. Delusion with communism, followed by disenchantment with a poorly sustained democracy that finally collapsed in Albania's quasi civil war of 1998 contributed to the establishment of an entrenched tradition of apathy, hopelessness, cynicism and moral relativism that strongly defines the way today's Albanians approach civic engagement, civic values, common good, merit-based systems, reward of performance and everything that actually underpins liberal democracy.

Since 2010 to the present, the reports produced under the Civil Society Index ${ }^{1}$ (CSI) show Albania's lagging behind the region in terms of human development, in particular as regards citizen engagement and levels of active citizenship. Several consecutive indexes reveal that the extent to which Albanian citizens engage in social and policy-related initiatives represents the weakest dimension of civil society. Young people are particularly affected by the low levels of awareness on civic values and civic engagement, that is reflected in their low level of interest in public causes or in volunteering. In addition to major structural deficiencies that accompanied Albania's transition from a centrally-planning system to an open market economy, civic education textbooks definitely represent a missing ring in the poorly built chain of elements that ought to lead to higher degree of awareness of civic values and civic engagement in Albania. In the following pages I will try to argue that the civic education curriculum and the civic education textbooks ${ }^{2}$ used in Albania are in themselves monumental examples of the auto-poietic reproduction of a pre-democratic society.

It should be noted that in the tradition of the teaching curricula in Albania, knowledge about society constitutes an aspect on which little or no understanding has been inherited by the former communist-bred pre-university education system. This particularly affects key social concepts and elements related to the democratic system, rule of law, division

\footnotetext{
${ }^{1}$ Civicus Civil Society Index Analitical Country Report for Albania, Institute for Democracy and Mediation, 2010 - 2014

${ }^{2}$ Albania's high middle school curriculum program for the classes 10-12 is divided into compulsory and elective curriculum. Civic education is part of the curriculum at 1st- 9th grades and of compulsory curriculum of 10th -11th grades each respectively developed by 1 hour/week and 2 hours/week. The civic education curriculum is considered as a prerequisite for the formation of students in social sciences grouped at the high middle education program as part of the elective curriculum including culture, sociology, psychology, philosophy, history, geography and economy. In addition from civic education, students of 10th and 11th class attend a compulsory course on Carrier and Living Skills Training supposed to deliver to the youngsters further training and living skills, but in fact is a repetition of the civic education text. (M.Poni, Analysis of the Stakeholders in the Albanian Educational System, 2011).
} 
of powers and civil society. Albania's National Education Strategy 2004 - 2015 was the last major post-communist largescale attempt to reform pre-university education. On curriculum development, the need was identified to develop a program focused on the knowledge and skills needed by students to function in an open democratic society. In 2009 the Ministry of Education and Science enabled teachers to use up to $10 \%$ of the planned class time for so called free topics ${ }^{3}$. Yet precious little was done to guide teachers on how to deliver these classes. One of the main issues for teachers was to understand and explain civic education concepts. This, in turn, is reflected to a highly problematic understanding of these concepts by the students. I tried to look into the issue through a study I conducted in $2010^{4}$, in the framework of which a survey instrument was administered to 500 students on the subjects of social and civic education 5 .

They were asked to give a definition of civic education. In $77.6 \%$ of the cases the students responded by trying to provide a definition of their own that described civic education as "the totality of the moral rules and norms that enable one to consider him or herself as a citizen". $20.8 \%$ stated that civic education is a subject of study that deals with social issues such as family, marriage, divorce or violence. Only $0.1 \%$ did not respond, whilst $1.5 \%$ responded that civic education helped them understand politics and institutions. They were further asked whether civic education texts actually addressed problems of everyday life, or whether they addressed them only superficially by failing to connect the concepts with the problems. To be noted that only $18 \%$ of the students considered them as concrete and related to everyday life. The rest (an overwhelming 79.6\%) thought the opposite. Further to analyzing the perceived impact of the civic education texts on the students, I surveyed the specialization of the teachers of social and civic education classes. There resulted that a large majority had a philological background. The distribution of the current teachers' specializations was the following:

- History-Geography $58,9 \%$

- Foreign Languages $5.8 \%$

- Elementary Education $15,3 \%$

- Social Sciences $10 \%$

The large majority of the surveyed teachers had not received any training or pursued any special education in the field of social sciences. Only $5 \%$ of those surveyed have received some sort of training on fields other than social sciences through the regional educational departments. I then proceeded to asked the teachers to rank in order of importance the subjects of "Social Education" and "Civic Education" in comparison to other study subjects, in a scale where 1 was the top score and 15 the lowest score. Following results ensued:

- $\quad 73 \%$ considered "Civic Education" as highly relevant (interval 1-3)

- 24\% considered "Social Education" and "Civic Education" as not particularly relevant (interval 8-15)

The teachers who considered "Civic Education" as not particularly relevant mostly taught history and geography. The very fact that $24 \%$ of the teachers publicly stated that civics or social education is not relevant gives considerable grounds to concern. It is clear that the perception of the teachers on the value of the subject of study greatly affects the students that reflects and multiplies it in his or her learning experience.

\section{Civic Education Textbooks}

Albania's civic education curriculum is used as the starting point for generating textbooks that might have different contents, whilst complying with the overall program requirements. Texts are produced in the framework of an open competition between publishing houses and are selected by schools. Although the curriculum program is unique, the texts reflecting it are not. The text production is commissioned by the Ministry of Education. The program orients the

\footnotetext{
${ }^{3}$ Directive No. 35 (2009) of the Ministry of Education and Science of the Republic of Albania

${ }^{4}$ G.Duma, Review of curriculum and methodology for the production of the social and civic education textbooks of ninth and tenth grade in Albania, 2010.

${ }^{5}$ The Albanian pre-university system for the grades 1-8 first underwent a radical reform in the year 1999: the system changed from 4+4+4 grades into 5+4+3, increasing the elementary education with 5 grades and decreasing the higher middle school with 3 grades. The new structure was meant to bring the Albanian pre-university system closer to the OECD standards. Albania's compulsory education of 9 grades prepares students for numeracy, literacy, communication, knowledge on health and social life, and abilities to become active members of community. The higher middle or secondary education of grades 10 to 12 aims at preparing students for their entry into the labor market or for the university education. The reformed curricula were enriched with new subjects, among which civic education, living skills and social sciences. (M.Poni, Analysis of the Stakeholders in the Albanian Educational System, 2011)
} 
publishing houses to draft the civic education texts. The production of civic education texts goes through a series of predetermined stages that involve several stakeholders from the Ministry of Education to the publishing houses, distribution companies, school directors and teachers. Even though on the one hand the Ministry of Education and Science approves of and legitimizes the existence of a number of alternative school texts (alter-texts), it actually endorses only one single program for all these texts to build on.

As a result, a number of alternative texts are produced that are bound to abide by the structure and contents requirements of one single program. This approach does not allow for sufficient flexibility. The situation concerning the social and civic education curricula is rather paradoxical. The differing philosophies and approaches in and around the Civic and Social Education texts on the one side and their respective programs on the other seem to undermine both the texts and the programs, by providing to the authors of the textbooks the possibility to try to attempt to push through changes to the school texts within the boundaries and limitations of one single program for each of the two subjects of study under our scrutiny. The ensuing competition between authors of textbooks was aimed at attaining some level of difference in the textbooks within a given and inflexible program gave rise to a remarkable lack of objectivism, taking into account that in such a situation, the priority was given to attain a text that differs from the other alternative text within the same program. This approach came to harm that pivotal element of the social sciences and the teaching methodologies that is objectivity. As a result of the quest for diversity, the authors of the textbooks of Civic Education and Social Education ended up trying to write schoolbook that were different each-other, by considering difference as an end in itself, whilst trying to abide strictly to the same program. This approach led them towards building phrases and explanations that are thoroughly subjective under the flag of uniqueness. Such an approach was highly detrimental to the scientific conceptualization of the schoolbooks.

\section{A Closer Look into the Subject of Civic and Education}

The structure of the program of "Social Education" taught to the ninth class has the following chapters:

1. Democracy, elements of democracy, forms of democracy, types of democracy, and practices of democracy.

2. Factors that assist democracy. Obstacles to democracy. Factors that support democracy. Democracy in Albania. Facing obstacles to democracy.

3. Functioning of democracy: Democratic functions, governing bodies, the legislative function of the Assembly, the executive function of the government, local government bodies and local governance, the function of the courts, role and function of the head of state.

4. Civic engagement, civic accountability, public interest, public policies, direct civic action, forms of civic organizations, civics and governance.

The program of "Civic Education" (tenth class) is structured along the following chapters:

1) The law and us 2)Constitution and Human Rights 3)Family 4) School 5) Childhood 6) Growth, change and adolescence 7)Labor relations 8) Environment 9)Health

With regard to the above structures a number of issues arise: Firstly, it can be argued that chapters such as Environment, Health, Childhood, Growth, Change and Adolescence might be of a better use in the social education rather than in the civic education program. Also, it might make more sense if the chapter "civic engagement", currently listed under the social education program, would work better under the civic education chapters instead. In addition to the redistribution of the key chapters and topics between the programs of the two subjects, there is an issue related to the chronology in which the key concepts are introduced. It is clear that the concepts that are introduced to the students of civic education ought to have been addressed in the social education texts first. The official program makes no allowance for an introduction chapter for both social and civic education textbooks. Such shortcoming in the program is reflected in all ensuing schoolbook texts.

As a consequence, the student receives a textbook entitled "Social Education", and upon opening it, he or she eyes a page that reads "Democracy". Well over $70 \%$ of the textbook covers issues related to democracy. The final chapter in the social education textbook is entitled "Civic Engagement". A closer analysis of the textbooks reveals that citizens' participation is presented to the students not as a social interaction among the actors of the society, but as an option that is made available to the society by virtue of a certain political system. The textbooks seem to presume that the society is not the originator and the working context of all institutions; it rather appears that society merely responds to certain institutions such as the state, constitution, the rule of law and so on. Therefore the textbooks convey a predominantly top-down message. They do not address the bottom-up interaction in the social hierarchy.

None of the texts, be these social education or civic education textbooks, manages to inform the student what the 
subject is about. The texts do not enable the student to see how ethics is established, how an ethical approach is build up, and how that impacts the organization and functioning of the society. There is a missing link between structure and contents. There are no actual and direct contextual links between program structures and actual texts. The students have to learn about democracy, rule of law, power and its characteristics, and the way these topics are embedded in today's society, but they cannot understand how these concepts should apply on their own behavior towards society. As a result, the factual responsibility for the transfer of knowledge remains at the discretion of the teacher who needs to decide what to teach and what not to teach. No allowance is made for measuring existing texts against actual results. The lack of baseline indicators in the texts is something that should be definitively noted. The texts do not possess measurement instruments. It is impossible for the student to assess him/herself throughout the text. The only self-assessment opportunity is given during the mechanical reproduction of the definitions of the concepts. At any rate, we will return to the issue of the missing of the measurement instruments in the section dedicated to the achievement of the text's objectives.

\subsection{Classes 10-11}

Civic education is part of the compulsory program and is taught in 2 years, $10^{\text {th }}$ and $11^{\text {th }}$ grade with 2 hours per week, and $11^{\text {th }}$ grade with 1 hour per week. The curriculum of civic education aims at 6 :

- Providing students with necessary abilities to understand, analyze and influence the social policy design and implementation;

- To develop student's capacity for active and responsible civic participation for community problem solving;

- To build up student's civic engagement for respecting common values, democracy principles and rule of law that is necessary for cohesive cohabitation in a democratic society.

Some of basic concepts of the civic education are: human rights, democracy, democratic principles, citizenry and sustainable development. According to the curriculum objectives, the concepts and information about civic education are not sufficient to craft the responsible citizen. The active citizenry is created through student participation in the community solving problems. The program of $10^{\text {th }}$ grade is organized through 9 lines: Law, human rights, family, school, children rights, childhood, work, environment and health. The program of $11^{\text {th }}$ grade contains 4 lines: food, consumer rights, road safety and the information rights. The program is considered to be integral. Especially, the $11^{\text {th }}$ grade program seems to be practice-oriented aiming at preparing students for living skills such as: food and health safety, road safety, consumer rights, and information rights. According to experts' opinions, the text of civic education at the $11^{\text {th }}$ grade is very basic for 17 years old gymnasium students. Compared to the civic education in the low middle school (i.e. $9^{\text {th }}$ grade), the curriculum of the gymnasium is poorer. The former addresses better the citizenship concepts.

From the chronological point of view, "Social Education" is taught to students of the ninth class. It is followed by "Civics" or "Civic Education" that is taught to the tenth class. These subjects of study are followed by other related study subjects, such as "Getting ready about life" and so on. "Social Education" and "Civics" are preceded by the study of other related subjects such as "Knowledge about society" or "Philosophy", the latter being a non-obligatory study subject. It is worth noting that these study subjects are affected by considerable duplications and repetitions of issues and themes, aggravated by a chaotic approach towards the key concepts. To better understand the situation, it suffices to note that in addition the subject of Civic Education, another course named Career and Living Skills quite similar to the civic education program of the $11^{\text {th }}$ grade is part of the compulsory programme. The aim of the living skills program is to prepare the students to conduct a healthy living style in order to avoid illness and other risks for themselves and others and to become environment protection activists. The similarity of programs has lead to the production of almost identical texts for Civic Education in $11^{\text {th }}$ grade and Living Skills in the $10^{\text {th }}$ grade. Because of the highly similar information given at these texts, students find them identical and as a repetition of each other. Consequently, students are almost indifferent to both courses.

The texts of the "Social Education" and "Civic Education" schoolbooks largely abide by the program approved by the Ministry of Education and Sciences. The conformity of the texts with the official program does not extend to actual contents or to their conceptual configuration. It relates only to a formal conformity with the structure of the topics and titles of the teaching hours. It also doesn't extend to the teaching methods that are developed in the different texts developed for the schoolbooks. All textbooks operate with highly abstract concepts, making a preliminary introduction to their substance coupled with prior knowledge on such concepts an essential prerequisite for a successful learning experience 
for the ninth and tenth grade students. The international best practices suggest that philosophy is considered as an obligatory subject of study in the pre-university education in the primary and high school education. In the case of Albania, philosophy cannot be of any help to the ninth or tenth grade students for the purpose of establishing the underlying concepts necessary for understanding the study subject. Therefore, a substantial part of the conceptual framework on social education and civics needs to be reviewed, so as not to end up in the realm of the self-explanatory. The self-explanatory approach, that is, taking for granted that some of the key concepts featured in the social and civic education schoolbooks are broken down by themselves, represents one of the biggest challenges to be met in order to create the necessary preconditions for establishing a valid knowledge basis for the student.

\section{Concepts}

In order to provide for a valid approach towards the conceptual contents underpinning the social and civic education schoolbooks, what we need to know is whether the student facing these key concepts can actually refer to some relevant chunk of knowledge, accumulated prior to the commencement of the study of civic and social education, or whether he or she is "tabula rasa" as far as civic and social education are concerned. For example, if a student comes across the term "democracy", it should be clear to him or her right from the beginning whether democracy as a concept is approached in the social/civic education text as a principle of social organization or as a political system. The difference between the societal organization principle and the political system principle cannot exist a priori in the student's mind. By expounding the principal concepts related to civic and social education as utterly distinct entities from the continuum of reality, and as something situated outside the historical development, these concepts are depicted as the only possible form of existence or as the only possible state of affairs, by thus preventing the students to figure themselves in the wider picture.

If the logical continuum and the understanding of the contextual relations of the basic tenets of civic and social education is missing, then the students have nothing to relate to. Students are thus left to themselves; they have no choice but to end up considering these concepts as given facts, to be taken for granted, and to be addressed as something that is not actually related to their personal reality. Therefore, even though in formal terms the texts of civic and social education appear to address the key concepts as relevant to their teaching objectives, and their definitions seem to be correct in general terms, they lack contextual arguments and fall short of enabling comprehension. These texts fail to involve the student as an active entity in the conceptualization process. It is clear that the issues tackled by the texts of civic and social education are relevant, but these ought to abide by a more logical sequence or escalation from their introduction to their explanation. On the other hand, besides the obvious problems related to conceptuality, context and comprehension, the texts of civic and social education display a number of faultily presented concepts, especially under the heading "key concepts".

Following cases of incorrect definitions of several key concepts can be used to illustrate this point:

Sovereignty - The highest independent authority.

("Civic Education" - Hysi, Andoni). This is a clearly incorrect definition of the concept of sovereignty. Even within the given terms and limitations, the definition of the concept of authority is missing. Therefore, besides giving a wrong account of the concept of sovereignty, the text takes the underlying concept of authority for granted.

General Elections - The right to vote that is granted to all citizens of legal age, regardless of sex or wealth.

Of course one might ask, among others, whether local elections differ in any way from general elections, if this definition is to be quoted.

Secularism - Impartiality and independence of the state from religions and religious consciousness.

It is self-evident that the above definition entails several shortcomings. The frequency of such definitions in the texts of social education and civic education is rather high. It should be here noted that in the texts on civic education key definitions are explained very sporadically. In many cases, definitions are only noted at the end of the text. No explanation or further clarification is given on their merit.

\section{Examples and Case Studies in the Civic and Social Education Textbooks}

The structure of the texts of the civic education and social education can be developed along two distinct paths. It is possible to start out with the theory and definitions on which to build the further discourse on the subject matter. It is also possible to start out with illustrations for the purpose of developing the concept at a later stage by building on the given examples. Even though the second approach seems to be more effective and communicative from the point of view of the teaching methodology, many examples brought forward by the authors are not satisfactory concept-wise. Very 
frequently these examples actually thwart the attempt to attain an objective and scientific definition of the issue addressed by them. Many examples strive towards fuelling the student's imagination and to motivate the student to interact, yet they risk bringing about a proceeding that lacks any actual product. In order to point up the above case, we refer to one of the introductory examples drawn on in one social education textbook (Ajdini and Duci). The first class of the social education starts out with the following example:

It's break-time. The students are enjoying the ball game in the schoolyard. When the bell rings, the students let go of the game, and head grudgingly towards the class. "Come in quick", says the teacher of the social education class, "this class is very interesting. We'll talk about democracy"." But, teacher", replies Suela, "doing classes at this time is not democratic at all. We have put it to vote and there resulted a clear majority in favor of hanging around in the schoolyard all the time, so that we can play ball".

This example sheds light onto several incoherencies that will be addressed in the following lines. At any rate, this example would be beneficial if:

1. It wouldn't be listed as the first presentation to the concept of democracy.

2. The teacher would possess genuine professional competence so as to be able to manage the process and keeping the balances needed for running the analysis of the exercise. In order for the teacher to be able to manage the exercise, he or she needs to have received sufficient formal training in the field of social education, and to possess a substantial teaching experience in this field.

From the logical coherence point of view, the exercise displays a number of problems. It should be noted that the action described in the exercise runs along the following phases:

The children interrupt the game and go to the classroom. They declare they have voted. Yet the decision of the voting round is to stay in the courtyard. Please note that the children actually stay in the class whilst pronouncing their decision.

Thus the students' decision, which is the consequence of a democratic procedure, has not been really enacted, taking into account that the decision to stay in the schoolyard has not led to any concrete action, on the contrary, the students are located in the classroom in violation of a decision taken through a democratic process that presupposes certain rights for them. As a consequence, the decision is merely pronounced, and no concrete application ensues. The reader would expect that the situation will be somehow remedied through the exit of the students. On the contrary, the exercise ends as follows: "The students' words made the teacher have some serious thoughts on democracy" (!!!). This is a clear case in point with regard to the lack of the coherence of the actions prescribed by the exercise vis-à-vis a logical and credible chain of events. On the other hand, this example implies that the students know already what democracy is, even though the concept of democracy would be developed further to the example. In addition to knowing what democracy is, the students know how democracy works. Indeed they know how the mechanisms of the democratic system, and they put them to good use to harm themselves. Thus, in the very first example of the social education schoolbook, the student faces a situation that well surpasses the mere introduction of the concept. On the other hand the example exposes right away the strong and weak points of the issue. In this manner the students that are interacting in the exercise apparently know well in advance how democratic procedures can be used in order to cast doubts on their participation in social institutions, such as the school and learning that constitute a key component of democracy. It should be noted that in this exercise, means seem to prevail over ends. Knowing democratic instruments is of course a necessary piece in the larger puzzle that is democracy; yet, they need to be approached in a critic manner so as to properly clarify the concept. Such examples, combined with totally unqualified human resources, such as the teachers in the Albanian schooling system, do not abide by necessary the methodical learning coherence. It is necessary to review and improve the way in which concepts and social phenomena are to be escalated in the student's mind-frame. This remains a serious challenge for the social education curricula as shown in the above example. The reference to the first option for developing the curricula (theory first, examples later) also displays a number of shortcomings. This comes as a result of the almost total lack of concreteness in this case. It should be noticed that such a lack of concreteness creates a considerable gap between the theoretical approach that is performed by putting forward a number of definitions that lack concrete and understandable applications. The structure of a class that is designed with reference to this option is the following:

\section{Title: Public Interest and Public Policies}

(A number of theoretical definitions of the concepts that are mentioned in the title are provided below the title)

\section{Sub-title: Examples}

(Under the subtitle, no examples are given. Instead, a number of further definitions that do not enable the student to concretely understand public interest or public policy are given, as follows): 


\section{Examples of Public Policies (from "Social Education" Authors: Ajdini and Duci, pg. 53)}

Public policies are generally applied by different governments for a number of reasons. For example: the education policy refers to the totality of the laws and regulations that direct the functioning of the educational system.

Social policies - refer to the instructions to create, change and maintain the proper living conditions. Social policies aim at improving the welfare and fulfilling human needs for education, health, housing and security.

These definitions are highly generic. They are vague not only at the practical, but also at the theoretical level, taking into account that the newly introduced concepts such as welfare, or "proper living conditions" deserve an explanation and clarification so as to avoid adding to the text further definitions with implied meanings, that totally undermine the students' ability to grasp them and the teacher's ability to send out the message in a concrete and meaningful manner. No cases of actual social policies are provided in the examples. It would be strongly recommendable to at least quote some actual policy or strategy and to address the way such policies and strategies are actually implemented, and the issues they refer to. This would be a more correct, down-to-earth method for enabling the student to get some taste of the development that affects his/her country. Nevertheless, the examples are given in a very similar manner as the one quoted above. The texts of the Social Education and one Civic Education text have plenty of such examples to offer. It is clear that such examples fail to provide anything that actually illustrates the real situation on the field, anything that transmits some actual meaning to the students. We face, times and again, the same generalizing, abstract situation, that fails to develop a concept into a reality. Such examples and illustrations are spread all over the texts that display severe gaps in terms of logical coherence, the escalation of knowledge. At times, the concept in itself is not addressed at all. Only its illustration is mentioned.

\section{Visual Elements and Illustrations}

In addition to the textual analysis of the Social Education and Civic Education curricula, we will also scrutinize their visual elements, as an important element for providing for concreteness and also for instigating students' imagination. The actual civic education and social education texts are dominated by photographs. Graphs, paintings and drawings occur less often. It would be advisable to use more paintings as part of the illustrations, so as to tap on the infinite variety that is offered by painting both in terms of metaphors and symbolism, especially when social science concepts are concerned. Tapping on these visual resources would help the further development of the students' imagination so as to promote a better understanding of the concept that is targeted by the study subject. On the other hand, the photos and the graphic illustrations that are actually used in the social and civic education texts are simple in terms of symbolism, and rather selfexplanatory. The message is conveyed at a superficial level, which does not respond to any real-life situation. On the other hand, a symbolic illustration would be more helpful to the teacher, as it would serve as a reference material or as a second text to rely on during the very short time at his or her disposal for the exploration of the key concepts. Not more than 15 paintings are used in the totality of the texts of social and civic education.

One of the most important aspects in this regard is the lack of the Albanian context in the most of the photographs that are used to illustrate the themes and the topics in the texts of the social and civic education. Those pictures that relate to Albania are mostly photographs of the front side of government buildings. The second most important group of pictures relates to the Roma families or to the vulnerable groups. In order to illustrate the meaning of the well-to-do family, all authors of the texts of the civic and social education seem to agree that the pictures to refer to should all be taken from the western world. In general the photographs that are used to illustrate the text convey a message of widespread poverty. It looks as if the whole of the society is in a situation of precariousness that necessitates the continuous support from the ruling class that enables the implementation of welfare policies that are measured against the minimum life standards. The society seems to be looking out for charity in almost all the photographs showing Albania. In many cases there are no captions below the illustrations. The sources are not quoted. No further explanations are given with regard to the illustrations. The illustrations are often not connected to the context of the situation they are supposed to depict. For example, in one Civic Education? text that addresses the topic "The law and the consequences of its infringement", complemented with the following sub-topics "The infringement of the law violates the rights of the citizens", "Consequences of the compliance and non-compliance with the law". The visual illustration to the above issues consists of a picture that displays the hand of a male who holds the hand of a female with a ring on it. This is supposed to stand for the marriage that is a relation between the spouses legitimized by the state. This illustration relates very indirectly to the actual topic. In theory illustrations should reinforce an idea or concept through a visual representation. 
The picture we referred to in the above example does not illustrate anything except for a static situation and a social fact that has no relation to the context.

Some illustrations suffer from real conceptual shortcomings, for example on page 30 of the text "Civic Education", the student comes across an illustration that bears the caption "Gravure from the year 1878, in France, the country of freedom: the worker gives away his rifle and exercises his right to vote". It is clear that "the country of freedom" has no connection to anything that is visible on the illustration. One cannot find anything that may attribute the illustration to France. The armed worker is a non-existing reality. It is not clear why the worker should bear arms. One can also hold true that the working class in France has not been engaged in armed conflicts over that particular period of time. By taking into account all possible explanations one can infer that maybe the illustration has a wrong caption that does not relate to it in any way.

\section{Level of Abstraction}

It should be noted that all textbooks of both subjects of study suffer from an over-saturation through abstract concepts that cannot be dispensed with through one or two pages. It should also be noted that the amount of pages dedicated to each topic/concept is limited by the program framework that is approved by the Ministry of Education and Sciences. Therefore, it can be maintained that the main responsibility for the failure to fully address the above concepts falls squarely onto the drafters of the programs of civic education and social education, before it trickles down to the authors of the texts. On their turn, the authors don't shun from squeezing into one single texbook page concepts that can be easily shown as tabling a high degree diversity between each-other on the top of an unnecessary level abstraction: majority ruling with safeguards for the minority, sovereignty of the law represented by the rule of law, everything on the individual and the dignity, sovereignty of the people and elections, separation of powers, justice, participation, and conditions of democracys.

Naturally enough, if only the titles are considered, one might be of the opinion that both curricula adopt quite an ambitious approach. If a student is in a position to receive such an amount of knowledge in one single class, then it can be well maintained that he or she will possess a substantive education in a number of dimensions related to democracy. Of course, in real terms, the above notions are only mentioned. In many cases the reference to such notion is concentrated to the extent that the student can hardly comprehend anything, or generalized to the extent that the student is not in a position to learn anything useful or applicable. Therefore it can be maintained that in view of the necessity to abide by the rules and limitations set out by the program, the school texts of civic education and social education provide either generalizations that do not provide for any substantive knowledge or highly concentrated abstractions that deform the concept to the extent of making it very hard to comprehend. To these shortcomings, language-related failures are added. These relate to the author's drafting and communication inabilities, and also to logical fallacies. For example in the chapter "Pro and Contra Arguments on Democracy", the author provides the following argument:

"In a democracy, the majority of the government is provided by people from different strata of the society. In many cases these people come from the lower strata. Taking into account that governance can be never in a position to fully satisfy their demands and interests, policies are derived that reflect these groups' discontent. These policies go against the general interest9"

It is clearly visible that this paragraph aims at addressing irrational policies. Yet this paragraph is the only one that refers to them. No more explanations on irrational policymaking is given throughout the text with exception of the above paragraph. One can only try to infer what this argument actually means. The argument contains heavy conceptual mistakes, such as "in many cases these people come from the lower strata". No clarification is given on this account, and since the reference is missing, this brings a considerable question mark on the argument. The above assertion brings about claims that do actual harm to the meaning and understanding of democracy. It impinges upon the core of the quality of the ruling majority in a democracy. As a consequence, a number of important questions on the quality of leadership and its vision arise. Of course there are moments in history when similar situation occur, yet this cannot be considered as a general principle. Also, a number of issues arise with the definition of the "lower class". Further, the author must clarify to what country and to what democratic system his assertion refers. In addition to this, the argument

\footnotetext{
${ }^{8}$ Social Education, Misha and Ibrahimi, page 12

${ }^{9}$ Social Education, Misha and Ibrahimi, page 14
} 
suffers from a lack of logical coherence. This is clearly visible by the juxtaposition of two sentences: "The majority of the government is provided by people from different strata of the society" one the one hand and "In many cases these people come from the lower strata" on the other. Same lack of coherence applies to the next sentence: "since the governance does not fulfill their needs". This does not make any sense, since the government has the actual power. Further, as these members of the government don't have their needs fulfilled by the same government, they start putting pressure on it. The argument means precisely this: members of the ruling government shape policy that reflects their discontent from the government! This is a rather blunt logical fallacy.

\section{Language Used in the Texts}

In general, the language used in the Social and Civic Education texts is highly formalistic. It does not differ in any way from the texts of the higher levels of education or from the texts used in the university. Most of the texts have in common a highly schematic language, in which the concepts seem to be framed, and still in need of a proper translation into Albanian. The language is not conducive to student's interaction. At times, sentences seem to miss the link to each-other. If we take a closer look, by the way of an example, at the textbook "Civics" (Dragoti and Sota) it will immediately spring to the eye that it uses a highly complex language and inscrutable phrases, such as "the exercise of the intermediation activity"10,"the right to social protection in the labor relations" 11, affective individualism"12,"categorical imperative"13.From the chapter "Dark phenomena in the family", we would like to single out following statements made under the heading "Divorce":

"If there exist no more share dreams on the future, then the spouses resemble "two trains running in opposite directions", or "In case the changes don't work in the same way on both spouses, then they resemble two trains running at different speeds" 14 ... "If there is no other option available, then people decide to go different paths, as they feel they'd be better off alone than together."

The metaphors spoken out in the above statements are worthless and utterly superficial. The heavy reliance on the comparisons does not transmit knowledge, but rather a superficial reproduction of routine slang. Throughout the text there is a noticeable tendency to merge simple and understandable language with highly abstract language related to the concept to be addressed. This merger takes place within a highly limited amount of available text. With regard to this phenomenon, let's refer to the following example:

"At times illegal actions are as severe as to be considered as criminal acts that are punishable by the state. In some cases, conflicts arise over property issues, contract infringements or tax issues, which do not require punishment, but rather a peaceful settlement of the conflict or compensation." 15

Using the phrase "at times" is an attempt to identify differences among crimes, so as to make a distinction between situations that are subject to regulation by law. At any rate, what comes through to the reader is that illegal acts not always are considered as criminal! Let's have a look at the next sentence: "In some cases, conflicts arise over property issues..." This sentence infers that the other cases related to conflicts have been previously addressed. In fact, the sentence focuses only on the illegal conflicts. On the other hand, the student is faced with the idea that conflict in this context represents an illegal reality!

\section{Impact on the End-user}

The social and civic education texts for the ninth and tenth grade do not rely on a genuine legacy from the Albanian education system. Social education has existed in some way in the school curricula of the pas twenty years under the title "Moral Education". From the point of view of the quality of language and chronology of the logical construction of the

\footnotetext{
10 "Civics" Dragoti and Sota page 114 paragraph 3

11 "Civics" Dragoti and Sota page 110

12 "Civics" Dragoti and Sota page 42

13 "Civics" Sinani, Hysi, Mano,Andoni page 45

14 "Civics" Sinani, Hysi, Mano,Andoni page 45

15 Social Education, Ajdini and Duci page 33
} 
concepts and knowledge that text has been assessed in positive terms in as far as it was effective in approaching its targets. Of course the moral education text and program of the past twenty years was not suitable for the development of a free individual in a democratic society. The positive assessment is related only to its actual ability to formulate the method for achieving its goal at that time. At any rate the inclusion of the new civic education and social education curricula in the curricula of the pre-university education represents a real opportunity for establishing workable knowledge that is needed for understanding today's society. Yet the question arises: Is it possible to understand today's society and to feel part of its reality and problems by reading the existing social and civic education texts?

In general terms these texts introduce the main notions related to today's reality, yet the key elements for the attainment of a workable knowledge on the subject are paradoxically situated in the question section at the end of the text. It is to be noted that the question sections cover the main issues that are common for all texts under our scrutiny. As a consequence, the key issues that call for a systematic concept analysis are subject of a number of questions relegated to the questions section, whilst their context is explored in a very superficial manner in the corresponding chapter of the text. At this point all question sections pose a serious challenge to the actual level of knowledge of the students. These questions are hard to respond even by a teacher who cannot rely on an own experience with social and civic education, or by a teacher who does not teach in this specific field of study, which is mostly the case in our education system. In order to provide more arguments on this tenet, we will refer to the questions sections in the social and civic education texts. One of the most commonly posed questions in these texts is the following:

\subsection{How do economic downturn and crime impact on democracy?}

Of course it is very necessary to explore this correlation, or, to put it in more correct terms, to highlight some actual evidence on this correlation. But posing a direct question on the impact on democracy by asking "How", is way beyond the student's ability to respond, especially by referring to what the student has been offered by the text. It would be advisable to reflect the current obligatory limitations of the text by pointing to the existence of such a correlation by providing facts and data related to the economic downturn, which, once a certain level is trespassed, impacts the criminality rate. Upon providing evidence as to the above correlation, the text might provide further proof on what sort of criminality is instigated by an economic downturn that pushes significant portions of the populations below the poverty line, and to what extent economic downturn can be read as a social injustice rather than a personal responsibility of a citizen that cannot manage to make a honest living. Of course, from here the text could build up a correlation with the local culture, and the local work ethics. Further arguments could be explored along these lines, so as to provide for a satisfactory clarification of the relevant concepts vis-à-vis a very challenging question to a ninth or tenth grade student, who is bluntly asked about the impact of economic downturn and crime on democracy. If a ninth or tenth grader is to respond to such a question, he or she would need to refer to additional information that is not available on a schoolbook. As a consequence, the student has no other choice but to refer to his or her daily contact with the mass media, in order to infer that the economic downturn actually reduces the chances to build a society that provides for social welfare and services. The lack of a genuine elaboration of the notions in the text cannot be countered by channeling all knowledge that is concrete and actual about them in the questions section, because such a practice establishes the dangerous precedent of getting answers without establishing valid points of reference in actual textual knowledge. It seems that the problems keep hovering on the surface of things, whilst the mechanisms to solve them are nowhere to be seen. The result to this is a subjective and wholly individual response from the student that fulfills the text's quest for interaction in the class.

In order to exemplify the above situation, let us refer to some questions that are asked in the texts:

- What are the causes for the failure of democracy?

- Why can decision-making, which is often in the hands of economic operators or influential international institutions, be imprudent?

- Who is influenced by political culture?

- "Freedom of the press is a blessing when we write against others, but a curse when others write against us". Why?

- Which are the main problems that affect secondary/university education?

In a democracy, an elite earns it ruling position:

1. Because of inheritance

2. Because of its special position in a given society;

3. Because it is the carrier of the truth 
4. By proving itself capable of representing the people ${ }^{16}$

A democratic government is not supposed to:

1. Regulate the production and utilization of human and material resources

2. Provide for housing and employment to all people

3. Support the progress and welfare

4. To ensure social harmony

These topics are designed to be used in the class for open class discussion or as homework. It is obvious that they considerably surpass the amount of knowledge that is imparted through the text. The above issues are introduced in a very premature manner to ninth and tenth grade students. The elaboration of these issues requires a solid, comprehensive, and very specific previous literacy on the subject matter. In addition to this, it should be noted that such topics are not supported by any previously imparted knowledge on the matter through the school curricula. It is critical to note that no definitive objective professional answer can be given to the above questions. In fact, in order to address the above questions, the genuine engagement of experts is required. The formal approach of the textbooks towards their subject-matter is highly reminiscent of the totalitarian regime, under which public discourse and the public engagement of the citizens were highly artificial, and coupled with an aversion towards reality and an out-of-the real word stand, that should be in each and every case inline with the guidance received from the party. Some aspects of today's public discourse on civic education and social values reflect that superficial level of civic engagement that was so characteristic of the totalitarian discourse. It is a specific and very distinctive feature of the totalitarian discourse to ask for direct answers to major issues on the grounds of minimum amounts of knowledge.

This mechanism strongly favors the establishment of a culture that lacks accountability towards its deliberations, towards its products, towards its obligations in the social dimension. It is a paradox that the prevalence of such a culture of failed accountability is promoted through the majority of the texts that are developed on civic and social education. Therefore the texts that are produced in this spirit end up bringing few concrete contributions and a missing concrete product, that is, they do not help students in establishing an active civic consciousness, that is the ultimate goal of the civic and social education curricula. The way questions are put is way beyond the students' capacities to meaningfully respond to them. Therefore, they are left with no choice but to respond to the questions in a manner that shuns accountability. If the student is offered only one or two pages with the description of the problems related to civic or social education, and if it is expected of him to learn some definitions by heart, than the result will be nothing more than a minimum engagement from the side of the student. As the demand for student's engagement constantly remains in short supply, as the student is not challenged to work towards attaining a good command of the study subject, his connection to the study subject is condemned to be weak. Also, the limited number of hours of study that is given to social and civic education exposes both subjects to a low profile vis-à-vis the other study subjects.

\section{Conclusions}

The aim of the "Social Education" and "Civics" curricula is to develop and to empower the students to get actively involved in civic and social life. The organisation of social life requires a solid knowledge on the fundamentals of the society, on the sanctioned rules and norms accepted by the society. It also requires a solid knowledge on the institutions that uphold the formal functioning of the society. From the formal point of view the texts of "Social Education" and "Civics" are compliant with the program established by the Ministry of Education and Sciences. The formal compliance with the current program does not essentially provide for the attainment of the required product. Furthermore the reality of one single program vis-à-vis the possibility of developing alternative texts makes bad use of the alternative texts. In many cases, some alternative texts have proven to be detrimental to the objective of the curricula, because their authors have tried to compete at all means within the limits of one single program, by exposing themselves to methodological fallacies. The authors of the texts of Civics and Social Educations should be actual researchers of civics and social sciences. There results that many authors of the current texts just write school books. They have no record of relevant scientific research in the field that is concerned by the actual curricula. This is an unacceptable standard. There results that the texts do not possess measurement instruments. The utilization of topics for discussions and examples cannot build on the actual contents provided by the text. The student cannot relate to sufficient materials for working out the correct answer to the questions made in the textbook.

${ }^{16}$ Social Education, Misha and Ibrahimi, page 5 
Supporting literature and valid reference materials are a significant precondition for the effective transfer of knowledge on civic education and social education to the students. In no way supporting literature should be limited to normative acts such as the Charter on Human Rights that can hardly metabolized by the student. The reference literature should include encyclopaedic materials and sources; it should be able to provide information on the social processes of different times and contexts; it should be literary enough to place the student within the atmosphere and context of a given social situation. Further, the materials downloaded by the internet in video or photo formats would make the subject matter more attractive for the student. The illustrations should respect at least two basic criteria: Firstly, they should provide a message with a clear symbolic representation that highlights the idea that underpins the text. Secondly, the illustrations should in no way be merely static images with only informative value, for example the photo of the cover page of the Constitution, or the photo of the façade of one or more buildings. The illustrations through photos should be dynamic and vivid, so as to incite the student's imagination and to trigger his reflection on the idea that underpins the text.

Nothing should be taken as self-explanatory, especially when complex situations are addressed, that are well beyond the student's capacity to comprehend. The examples ought not to be intricate labyrinths implying the synoptic discussion of multiple dimensions. The examples should enable for an application of a clear analytical capacity. They should not provide a distracting variety of options that remove the fundaments of analysis and prevent the student from working out some realistic viewpoint on the matter, by leaving him out in the cold in a situation of total relativism. Even though contextuality and relativity are two key dimensions in the organisation of social life, we believe that the establishment of solid viewpoints and analytical discussion capabilities should not be overly minimised. It is clear that perfect textbooks will not suffice to achieve the goal of an active citizenry if the teachers are unable to draw upon sufficient professional qualifications. One of the key issues to be grappled with is the qualification of the teachers of civic and social education. If the current situation in which over $80 \%$ of the teachers deliver civics and social education classes only because they have to fill their teaching program, is to persevere, then the effort to establish a viable product that leads to active citizenship will continue to yield poor or negative results. With regard to the above considerations, it can be surmised that no learning process aimed at more civic consciousness enabling for an active citizenry can be accomplished through the existing curricula. Its contents are formal and declarative, and the teaching methodology does not comply with the standards of incremental transfer of knowledge. At their best, these texts provide dry and often wrong formulations of the concepts of civics and the social and political organisation of the society. They do not involve the students as active stakeholders. The crushing majority of the teachers of civic and social education are not in a position to meet the challenge of achieving a goal that is clearly beyond their professional capacities.

Civic engagement can not be developed as long a society and its organisational system are represented as given and static state of affairs in the textbooks; no valid knowledge on society can be transmitted to the students, as long there is no understanding on how structures and institutions are created. If the organisation of the social life is not understood as a product of the society, then society itself becomes meaningless. This reflects on the individual, by transforming him into a being that is not interested in the development and functioning of his habitat.

Civic education curricula in Albania constitute a monument to the perpetuation of a "natonal" culture of civic apathy and social disengagement. The manner of their production stemms from a hidden system file that cannot be overwritten; it inherently and continuously reproduces a formalistic and empty account of values of liberty, society and democracy. There are deep-rooted framework conditions reasons behind the processes, stakeholders, players and mindsets that end up generating a widely inefficient framework for civic education in the institutions of middle education of Albania. Albania's civic education texbooks for grades 9 to 11 are a consequence of the continuum of the autopoietic re-production of a closed society; they are in themselves few rings in the long chain of causes and consequences leading to the perpetuation of the problems they are meant to contribute in solving. 